\title{
Planning for Nation Wide Dissemination of Robotics to SMEs
}

\author{
Jens VON AXELSON ${ }^{\mathrm{a}, 1}$, Sandra MATTSSON ${ }^{\mathrm{b}}$ and Björn LANGBECK ${ }^{\mathrm{c}}$ \\ ${ }^{\mathrm{a}}$ The Swedish Agency for Economic and Regional Growth and Sweden's Innovation \\ Agency, Vinnova \\ ${ }^{\mathrm{b}}$ Research Institutes of Sweden, RISE IVF \\ ${ }^{c}$ The Swedish Agency for Economic and Regional Growth
}

\begin{abstract}
This paper describes how a special assignment from the Swedish government was carried out to support small and medium sized enterprises in implementing automation and robotics. The focus of this paper is to investigate i) how insights and knowledge has been transferred and ii) how the ability of integrators and advisors has been increased. Within the project Pilot project automation challenge in the robot leap (PILAR), 84 pre-studies and 40 indepth studies were carried out. In PILAR a methodology was developed, and a way of working was tested where coaches in four regionally defined nodes in Sweden visited companies and had advisor support through telephone and video. The project results indicate that insights and knowledge had been increased in several companies and that integrators and advisors have increased their ability to stimulate automation solutions. In addition, eight recommendations on how to successfully perform a nationwide dissemination of robotics is presented.
\end{abstract}

Keywords. Automation; robotics; dissemination; digitalization.

\section{Introduction}

The rapid development connected to Industry 4.0 and digitalisation offer potential but also many challenges for Small and Medium Sized Enterprises (SMEs). Potentials are seen connected to that technologies such as collaborative robots and automation are more capable and inexpensive [1-2] and examples of successful digital transformations show increases in efficiency, quality and new business. The potential has increased significantly also for companies where it has previously been challenging to introduce automation solutions. This is especially noticeable in Denmark, which shows a rapid robotization rate in recent years. Although technologies are ready and available, they are many times not adopted in the manufacturing industry [3].

The adoption of new technologies is a challenge for SMEs since they are often illequipped to manage digital transformation in their production planning and control functions [4]. One reason for this may be that they usually have less resources and does not always know how automation and robotization could contribute to strengthening their competitiveness. Small companies are subject to greater external uncertainty and greater internal consistency of motivation and action than large companies. This stems from that small companies often have large company customers and that the large gives

\footnotetext{
${ }^{1}$ Corresponding Author, jens.vonaxelson@vinnova.se.
} 
small companies little bargaining power. This in turn leads to that the SME should be more reactive to the business environment and will have to redesign itself more often [5]. In general SMEs differ in three ways from larger companies: management, resources and organisation. Regarding the management of the SME several authors have concordance in their findings [6-11]. SME management seems to be small and centralised. A shortrange perspective makes it easy to be absorbed by details. SME mangers have in general a high commitment, but the management skills vary. However, the management in an SME is an important factor to consider in the implementation of new technology. Problems and obstacles occur if the management team does not participate in the implementation process. SMEs have limited resources, both financial and manpower [9, 12-15] and they often need external support if they want to implement new technology.

This paper will describe the design of a program based on the Swedish government special assignment [16] given to increase the degree of automation in SMEs nationwide. An important aspect of the dissemination is if, and to what extent, the program facilitated for SMEs to implement automation and robot solutions and what insights that have been captured throughout the program.

\section{Governmental special assignment and developed program}

On $25^{\text {th }}$ of January 2018, the Swedish Agency for Economic and Regional Growth was commissioned to develop and implement a program for a Robot Leap ${ }^{2}$ [16] aiming for the promotion of automation and robotization in manufacturing SMEs. The program should be built on lessons learned from realisation of the Digitization Leap ${ }^{3}$ and regional projects that have been conducted with this purpose, such as the Automation Challenge ${ }^{4}$ and the Production Leap ${ }^{5}$. The program should reach a significant number of companies with good geographical distribution and help companies increase their knowledge of the use of and investments in automation solutions. Automation is here referred to in a broad definition. The goals of the program are stated as:

- Increased insights and knowledge for many companies about the potential of automation for their competitiveness.

- Increased ability of automation system integrators and advisors for the target group to stimulate better automation solutions in the companies.

The belief in that utilizing opportunities for robotization and automation of the production flow is necessary for companies in industry to be internationally competitive. The long-term goal for companies in the target group then was to increase the use of modern automation solutions in their production systems and thereby improve their competitiveness. According to statistics from Eurostat [17], large enterprises uses robots more $(25 \%$, more than 250 employees) that medium (12\%) and small sized enterprises (5\%, number of employees 10 to 49). In EU the highest number of industrial or service robots are seen in Spain (11\%), Denmark and Finland (both 10\%), and Italy (9\%). The Swedish automotive industry has adopted automation relatively well according to the

\footnotetext{
2 Robotlyftet (in Swedish)

${ }^{3}$ Digitaliseringslyftet (in Swedish)

${ }^{4}$ Automationsutmaningen (in Swedish)

${ }^{5}$ Produktionslyftet (in Swedish)
} 
statistics, but in other parts of Swedish industry there is more to do when it comes to taking advantage of the possibilities of modern automation and robotization.

\subsection{Scope}

Based on the objectives of the program the following topics are investigated in this paper:

1. What insights and knowledge has the pilot project (PILAR) reached for the governmental assignment as a whole?

2. How has the ability of integrators and advisors for the target group been increased by stimulating better automation solutions?

As a conclusion, basic principles for a nationwide program should rely on is presented. To support this investigation technology dissemination and the SME context is presented in the following section.

\section{Technology dissemination and the context of SME}

There are different models used for describing technology diffusion. The diffusion of technology is measured as the cumulative number of adopters and conforms usually to an exponential curve. The exponential pattern could be in three different shapes: simple exponential, modified exponential and S-curve [18]. The most common ones used to describe technology diffusion is the S-curve [19-20]. The S-curve is characterized by a slow initial growth, followed by a rapid growth after a so-called take-off point and then again slow growth until an upper limit.

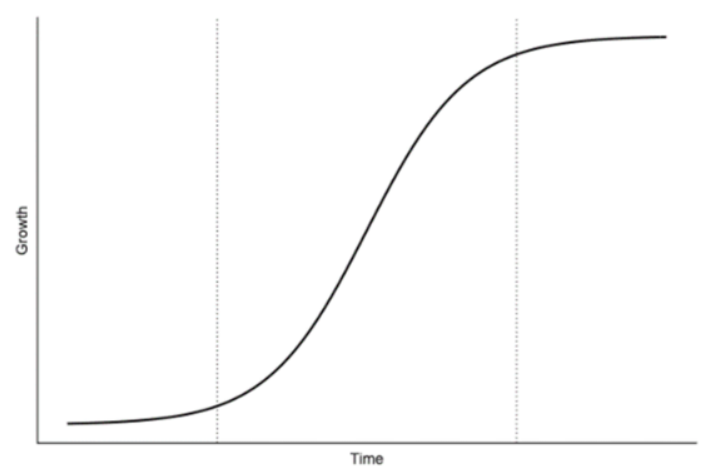

Figure 1. A principle S-curve as it often described.

There are several descriptions and mathematical expressions of the S-curve such as: The Bass model, the Gomperetz model, the Logistic model and the Pearl model [18]. However, Damsgard and Lyytinen have in a study regarding EDI diffusion in Finland concluded that technology diffusion is a mixture of institutional, technological, socioeconomic and cultural factors which current diffusion models have difficulties to describe [21]. In situations where there are several connected potential adopters, like in an industrial network, they suggest multiple units of analysis and multiple levels of 
theory to deal with this problem. Hence, technology diffusion is a complex area. Technology in general have a broad range of characteristics, from large systems to a single manufacturing technique. It is therefore difficult to predict a detailed diffusion pattern for the type of technology that production methods constitute. The diffusion process implicates that potential adopters make adoption decisions.

A general process of innovation-decision is presented by Rogers and describes the adoption of innovations in five steps [20]:

1. Knowledge, i.e. acquire the knowledge of the existence of the technology

2. Persuasion, i.e. the potential adopter gets the possibility to grasp the technology's characteristics and understand its potential in relation to the own production system

3. Decision, i.e. the potential adopter test the technology and decide whether it should be implemented or not

4. Implementation, i.e. the adopter builds up necessary competence to implement the technology in the business context

5. Confirmation, i.e. the adopter use, standardizes and improves the technology and seeks reinforcement of the innovation-decision

The steps 1-2 regard both knowledge and understanding the potential of a technology which is connected to the first research question in this paper. Step 3 and 4 are coupled to the second investigation topic. The ability to stimulate better automation solution could be connected to the increased ability of integrators and advisors. The fifth step can be investigated in a later step of the dissemination due to that it is believed that the true confirmation of the technology diffusion can be seen when technology is in a more mature face of its development.

The adopting companies' characteristics are used to describe the diffusion process and divide them into five groups: Innovators, Early adopters, Early majority, Late majority and Laggards, Figure 2. The classification is a result of the need to describe that different companies have different ability to, on the one hand, acquire the knowledge about new technology and, on the other hand, have different capability to grasp and adopt.

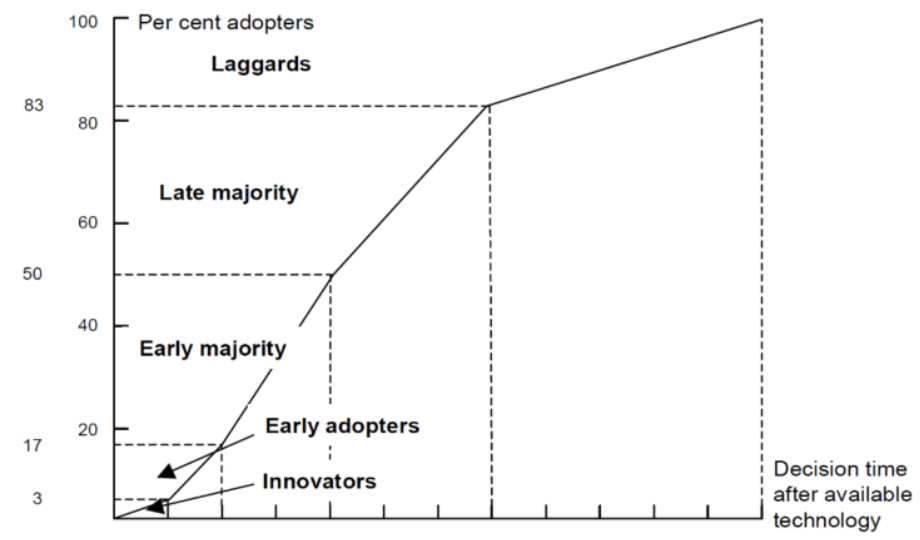

Figure 2. Technology diffusion and classification of adopting companies (adapted from [20]). 
Some small companies are innovative and early adopters, but many of the SMEs are late adopters meaning that they have needed a longer decision time after automation solutions and especially robots are available on the market.

\section{Initiation and program design framework}

This section describes the program principles and development of the pilot project PILAR, Pilot project automation challenge in the robot leap.

\subsection{Program principles}

The purpose of the government assignment was, as stated above, to design and implement a program to promote automation in all parts of the industry's small and medium-sized companies in Sweden. The program should reach a significant number of companies with good geographical distribution and help companies increase their knowledge of the use of and investments in automation solutions. Many industrial businesses need knowledge to work more efficiently with modern automation solutions, as well as to develop the digital opportunities in their business. Analysis of data linked to your own business can, for example, lead to opportunities to optimize production processes. The change theory for the program is shown in Figure 3 below.

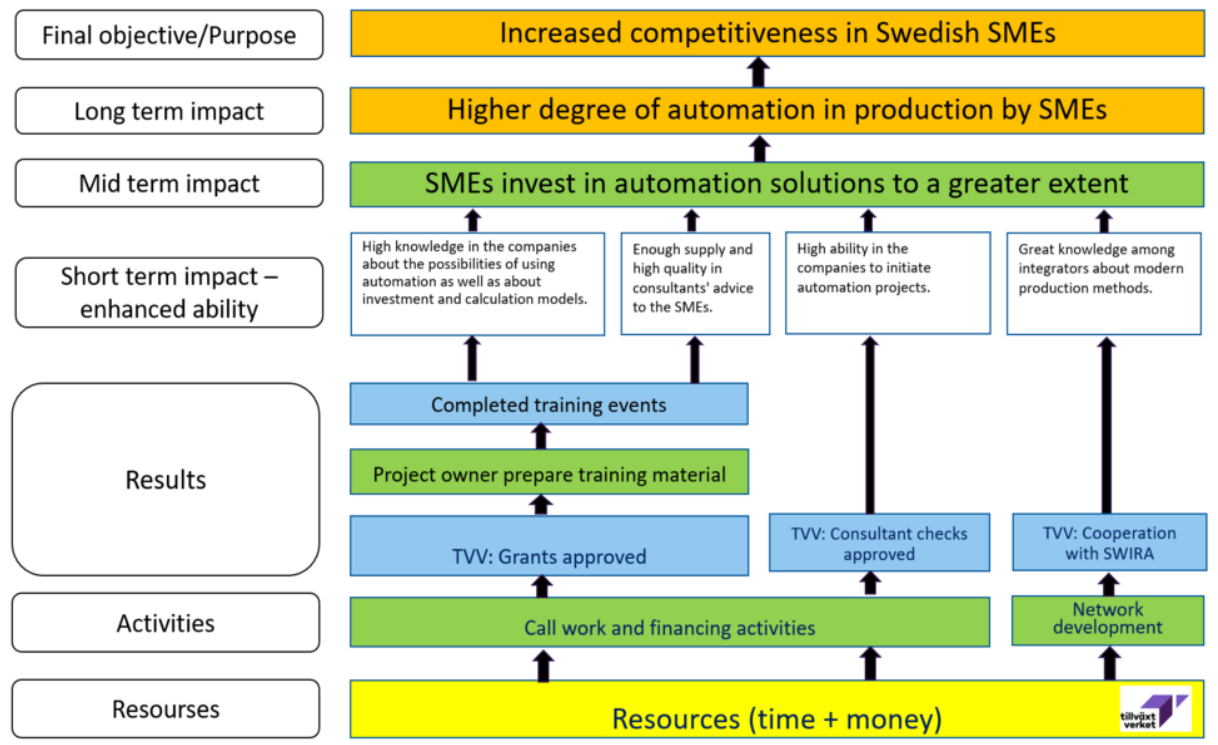

Figure 3. Framework and change theory for the programme planning process at The Swedish Agency for Economic and Regional Growth.

The program plan describes four major programme tracks: Training, Advisory, Technical consultancy and Network development. 


\subsection{PILAR}

The aim for PILAR, was to increase SMEs opportunities to strategically choose the path in the rapid development of automation and robotization. The pilot project PILAR duration was 9 months (May 2018 to March 2019) and the aim was to develop a general method for strengthening the companies' opportunities as a first step to analyse and choose the path in the development of automation and robotization. PILAR also tested how a platform for collaboration can be designed between the project parties IUC Sweden, Robotdalen, the research institute SWEREA IVF and Automation Region, to reach industrial SMEs throughout the country. The development method tested by some eighty companies in four regions will increase their knowledge and ability to develop and innovate in applications of automation robotization. For those companies that choose to proceed to decisions on automation / robotization, the process leads to a tailor-made proposal for implementation and relevant education. Tailor-made tutoring at a distance and on-site at the companies is an essential part of the method. The project's knowledge, experience and tested working models should contribute to the possibilities to quickly create an expanded and multi-year program, to promote automation and robotization in SMEs.

\subsection{Pilot project realisation}

The pilot project was built on a regionally implemented project run in 2017 where Robotdalen, IUC Dalarna AB, Swerea IVF, University of Gävle and The University of West collaborated with selected industrial SMEs and students at Mälardalen University. In the PILAR project, the challenge was to scale up, in a first step, the regional project to four more regions across Sweden. This also meant that methods, tools and forms of co-operation had to be developed to achieve rational working methods. At the same time, the focus was on initiatives that can contribute to small and medium-sized businesses industrial development. This meant that the pilot project in its objectives had to test and develop both new ways of working to reach SMEs, utilize existing knowledge in society and activities for increased collaboration and shaping tools that meet the needs of SMEs and issues.

The target can be split into the following parts:

1. Form a composite program and working method to contribute knowledge, analyses, demonstrations, and development proposals for industrial SMEs in four regions throughout the country. The program will test and implement practical measures as well contribute to forms of collaboration between actors with different resources and contact networks.

2. Fulfil several quantitative indicators with a clear focus on activities intended to act as a development chain for the benefit of SMEs which are at different levels of knowledge about automation and robotization in their own operations.

The target set were:

- $\quad 84$ SMEs should be identified and undergo pre-studies

- 40 SMEs should be able to be selected and offered an in-depth pre-study 
- 120 representatives of SMEs should be given the opportunity to participate in inspirational lecture and/ or mini exhibitions. 4 minimums automation expos or mini exhibitions should be arranged

- 56 people from SMEs should be given the opportunity for in-depth training in automation and client competence

- 4 regional nodes should be formed with 8-12 mentors meeting SMEs

Method development goals that were designed were to develop and apply one common tool for conducting analyses together with SMEs, and test and evaluate work methods to be able to work remotely in collaboration between companies - mentors experts.

\subsection{Organisation}

A project group was formed with representatives of the collaborative operations. The project group's main goal was to coordinate efforts, development, planning etc. to avoid parallel efforts and utilize resources to develop common platforms. The project group has had specific time allocated for its distance meeting every 2 weeks. The design of the in-depth pilot projects the nodes were: South, southern central Sweden, northern central Sweden and north. In each node, a person has acted as a node coordinator, which meant being the person who follows up the planned efforts, compiles and is responsible for the input of reports, become the main project manager's contact for administrative and practical issues and participate in planning of ex. exposure, training etc.

\subsection{Sample}

84 SMEs went through a pre-study and 40 SMEs went through the method developed in PILAR. The sample SME was classified according to their size where 59\% was SMEs, $49 \%$ produced their own products, $38 \%$ were suppliers, $22 \%$ were medium sized, $14 \%$ was micro sized, $3 \%$ were service companies and $4 \%$ was classified as other.

\section{Results}

Within PILAR, a guideline was developed for performing a pre-study and in addition a working method was tested and developed that included four nodes in the $\mathrm{IUC}^{6}$ (managing the project). Connected to the project four automation expos were carried out in the four nodes and four education sessions were developed and carried out aiming to increase the automation competence and SME ability to choose better automation solutions.

\footnotetext{
${ }^{6}$ Swedish network of Industrial Development Centres, www.iuc.se.
} 


\subsection{SME needs}

After summarizing the need specified by the SMEs the following figure was drawn stating what priority areas 79 companies identified as priority 1, 2 and 3, see Figure 4.

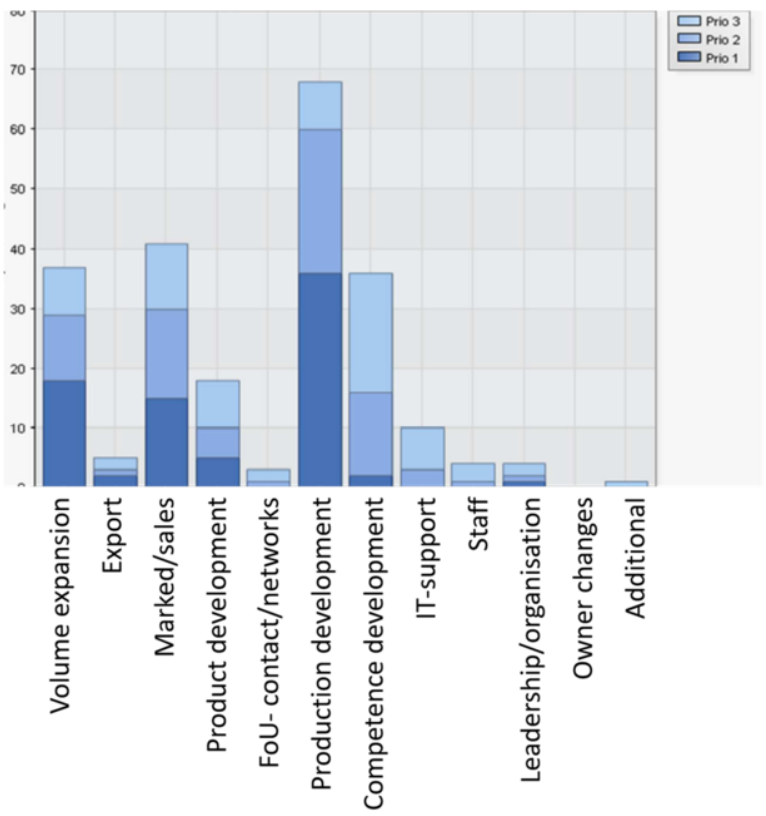

Figure4. Prioritised needs specified by the SMEs.

Most companies identified a need for production development as priority 1, then came volume expansion and marketing and sales. Production development was also rated highest for priority 2 and then came marketing/sales and competence development (also high for priority 3 ). The regional coaches, having a pre-knowledge of several industrial companies in the region, ranked the companies in the pre-study as having a good view of the company's current state. The companies had a clear view of their business with good knowledge of their customers and market, insights in and know the possibilities for competence development which could be needed, a need for automation/robotization to increase work environment or ergonomics and products suited for automation or robotization.

\subsection{Insights and knowledge}

The quantitative goals were met according to Table 1 .

Based on the table, impact areas were identified in which chosen companies participated actively in gathering data together with the coaches in the pre-studies. In addition, in total 79 participants were educated in automation and education in ordering automation and robotic solutions. 
Table 1. Quantitative goals for PILAR.

\begin{tabular}{|c|c|c|}
\hline Target & Goal fulfilment & Comment \\
\hline $\begin{array}{l}84 \text { SMEs should be identified } \\
\text { and undergo pre-studies }\end{array}$ & $\begin{array}{l}84 \text { SMEs was identified, and } 75 \\
\text { SMEs underwent a pre study }\end{array}$ & $\begin{array}{l}\text { The goal was fulfilled, and a } \\
\text { geographic sample was } \\
\text { performed with 19-22 SMEs } \\
\text { from each node. }\end{array}$ \\
\hline $\begin{array}{l}40 \text { SMEs should be able to be } \\
\text { selected and offered an in-depth } \\
\text { pre-study }\end{array}$ & $\begin{array}{l}40 \text { SMEs were selected and } \\
\text { offered a pre-study. } 37 \text { pre- } \\
\text { studies were completed, and } 2 \\
\text { SMEs were connected to a } \\
\text { development program and one } \\
\text { company was seen to not qualify } \\
\text { for a pre study. }\end{array}$ & $\begin{array}{l}\text { All selected companies actively } \\
\text { took part in the studies and } \\
\text { contributed with their } \\
\text { information. More candidates for } \\
\text { automation/robotics was } \\
\text { discovered. }\end{array}$ \\
\hline $\begin{array}{l}120 \text { representatives of SMEs } \\
\text { should be given the opportunity } \\
\text { to participate in inspirational } \\
\text { lecture and/ or mini shows }\end{array}$ & $\begin{array}{l}\text { Four automation expos were } \\
\text { carried out with more than } 100 \\
\text { SMEs and } 273 \text { visitors. In } \\
\text { addition, } 9-15 \text { exhibitors were at } \\
\text { each event. }\end{array}$ & $\begin{array}{l}\text { The goals were exceeded and } \\
\text { had good recommendations. } \\
\text { Requests for more expos has } \\
\text { been noted. }\end{array}$ \\
\hline $\begin{array}{l}56 \text { people from SMEs should be } \\
\text { given the opportunity for in- } \\
\text { depth training in automation and } \\
\text { client competence }\end{array}$ & $\begin{array}{l}\text { Four educations (one in each } \\
\text { node) were performed with } 79 \\
\text { participants that received } \\
\text { training in automation and client } \\
\text { competence in } 1,5 \text { days where } \\
\text { theory was mixed with labs and } \\
\text { demonstrations. }\end{array}$ & $\begin{array}{l}\text { In some of the educations there } \\
\text { were more than } 20 \text { participants, } \\
20 \text { should be a limit. }\end{array}$ \\
\hline
\end{tabular}

It is relevant to note that insights and knowledge was spread in increased through the organisation of PILAR which made it possible for the coaches, with their regional knowledge, to connect with expert functions through e.g. institutes and universities.

\subsection{Ability for integrators and advisors to suggest better automation solutions}

The ability for integrators was not systematically increased. In the project coaches/mentors were found and took part in the project. For introduction of new mentors, the education was filmed. Additional three coaches/mentors were recruited during the project. It was seen that the access to additional coaches within the nodes reduced the vulnerability for the project and in addition discussions regarding different solutions could be performed.

The ability of integrators and advisors has contributed to better automation solutions through the following:

- A common tool exists that an organisation collaboratively has developed

- The tool scans both the company's strategic position and their productivity development possibilities

- The way of working leads to new possibilities in common learning since re-use of the method brings new details

- SMEs are not left with commercial options since the expert organisations are not profit driven 


\section{Discussion}

What insights and knowledge can be drawn from both the theory of Innovation diffusion and the pilot project PILAR? Many SMEs seem to be late adopters since they have needed longer time to implement new automation and robot solutions [17]. This could be due to that they have limited resources [9, 12-15]. From a technology dissemination view they therefore need knowledge and persuasion [20] which they were given through the activities in PILAR (see Table 1). The PILAR project can be seen to have increased insights and knowledge for SMEs in this way, indicating an answer to the first topic in the scope of the paper.

Before SMEs can reach implementation, they may need to test the technology to decide to invest. They may also need to build necessary competence regarding the technology in a business context [20]. These two steps are connected to the second investigation topic "How has the ability of the integrators and advisors for the target group been increased by stimulating better automation solutions?"

The integrators and advisors have important roles in both presenting different solutions, i.e. providing knowledge, and in the persuasion and later decision process. It is also necessary that the advice is neutral from a business point of view and that integrators focus on the target groups needs rather than a business opportunity for themselves.

\subsection{Recommendations for implementation of automation and robotic solutions}

The following recommendations were given by the leading parties of the PILAR project. It is recommended to follow the 8 steps but adapt each effort and choice of route to the local company's conditions:

- Identify SMEs

- Verify the company's SME status and financial status

- Contact SME and plan the initial visits and appoint a contact person at the company. May be preceded by discussion over the network or telephone to possibly identify which one (s) areas in the production flow that are most urgent to touch. It can mean an early contact to identify a co-judge

- Self-assessment performed by SME - sent, if needed, out in advance to the company for a visit together with a work plan for implementation of pre study

- Visit the company

Review of the self-assessment basis, the current situation and the target image of the company. An overall scanning of the strategic position om the SME is made to identify automation candidates in production, preferably with photo and filming. Documentation is done with a uniform report template. Contact with co-assessor is taken, vi) Continued analyses and retrieval of input data - through additional visits, via web and or telephone. The goal for this phase is to produce facts to prioritize one of robotization /the automation candidates and assess opportunities for the next step based on this candidate. Coexaminer / expert is now appointed and participates in meeting (on site or distance), vii) Write and send report summary with advice on the next step to co-examiner. Documentation according to the guideline is designed in a prerequisite study report as 
includes evaluation and advice on continuation and viii) Information on the application for automation check - feedback of report and discussion and planning of continued efforts with Automation check. IUC serves as support and interlocutor. The issue of the company's status about the EU The rules for negligent support are updated.

The main program development from the first program Robot to 1000 until Robot leap is the focus on expert services. In the Robot to 1000 about one out of three studies resulted in an actual investment. The aim behind the program robot leap is to increase the number of investments in relation to the studies performed. As a next step automation vouchers could be applied by companies. There has not been set a formal target for the ratio between the number of approved automation vouchers and investments. Despite the absence of a goal this is the most important outcome of the program and it must be measured.

When starting new programs there is a first stage to introduce the program and present it to the target group. It is not unusual that an invitation to an information seminar results in very few attendants. This has, until now, not been the case with robot leap. There are a few possible solutions to this, each which could be investigated. Firstly, automation applies to the core processes in the companies. Robots are known but not exactly how they can be implemented in the company. Secondly, some of the partners in the program has long time relations to several companies, i.e. some are already in CRM systems. Thirdly, SWIRA has been organising a biannual conference on robotics for many years. The last three have had a special focus on robots in SMEs. Fourthly, there are at least some 40 systems integrators in Sweden working in the field of robot installations in SMEs. There is so to speak already marketing activities ongoing. Despite these facts the number of companies wanting a pre study performed at their site is as expected but the number of approved automation checks are lower than expected.

\subsection{Reflections}

Although the captured empirical data show indications of that insights and knowledge in automation and robot solutions can be increased the results of the program cannot fully be seen until three or four years. This is when companies could have implemented the solutions and the effects of the program can be seen. Hopefully, it will be seen that the special assignment and PILAR project would be cost efficient and that Swedish SMEs will have increased the number of robots in industry by $20 \%$. To be able to efficiently support SMEs an update of robot solutions is needed and, in the future, a good connection between researchers and technology suppliers are needed.

The questions were investigated through empirical data. By collecting data this way, the choice of sample plays a role in the results presented. It is the authors belief that the results present a unique view of the sample's knowledge level and needs in industry today.

\section{References}

[1] D. Romero, J. Stahre, T. Wuest, O. Noran, P. Bernus, Å. Fast-Berglund and D. Gorecky, Towards an Operator 4.0 Typology : A Human-Centric Perspective on the Fourth Industrial Revolution Technologies. Int'l. Conf. on Computers \& Industrial Engineering (CIE46) Proceedings, Tianjin/China, 2016, pp. 1-11.

[2] A. Kolbeinsson, J. Lindblom and P. Thorvald, Missing mediated interruptions in manual assembly: Critical aspects of breakpoint selection. Applied Ergonomics, vol. 61, 2017, 90-101. 
[3] S. Weyer, M. Schmitt, M. Ohmerm and D. Gorecky, Towards Industry 4.0 - Standardization as the crucial challenge for highly modular, multi-vendor production systems, IFAC-PapersOnLine, Vol. 48, Is. 3, 2015, pp. 579-584, ISSN 2405-8963, Available: https://doi.org/10.1016/j.ifacol.2015.06.143.

[4] A. Moeuf, R. Pellerin, S. Lamouri, S. Tamayo-Giraldo and R. Barbaray, The industrial management of SMEs in the era of Industry 4.0, International Journal of Production Research, 56:3, 2018, pp.11181136, DOI: 10.1080/00207543.2017.1372647.

[5] J. Bradford and S.J. Childe, A non-linear redesign methodology for manufacturing systems in SMEs, Computers in Industry, Vol. 49, 2020, pp. 9-23.

[6] A. Ghobadian and D. Gallear, TQM and organization size, International Journal of Operations \& Production Management, Vol. 17, No. 2, 1997, pp. 121-163.

[7] R.C. Macgregor, Factors associated with formal networking in regional small business: some findings from a study of Swedish SMEs, Journal of Small Business and Enterprise Development, Vol. 11, No. 1, 2004, pp. 60-74.

[8] D. Penn., W. Ang'wa, R. Forster, G. Heydon and S. Richardsson, Learning in Smaller organizations, The Learning Organization, Vol. 5 No. 3, 1998, pp.128-137.

[9] H.B. Marri, A. Gunasekaran and B. Kobu, Implementation of computer-integrated manufacturing in small and medium enterprises, Industrial and Commercial Training, Vol. 35, No. 4, 2003, pp 151-157.

[10] J. Forslin and B-M. Thulestedt, Lärande organisation - Att utveckla kompetens tillsammans (In Swedish), PUBLICA, Stockholm, 1993, ISBN 91-38-92176-6.

[11] H. Ylinenpää and L. Lassinatti, Academia facing small business reality - a study from the perspective of University Trainees, AR 99:36 Luleå University of Technology, Dept. of Business and Social Sciences, 1999.

[12] H. Shield., R. McIvor and D. O'Reilly, Understanding the implications of ICT adoption: insights from SMEs, Logistics Information Management, Vol. 16, No. 5, 2003, pp. 312-326.

[13] L. Alstrup, Coaching continuous improvement in small enterprises, Integrated Manufacturing Systems, Vol 11(3), 2000, pp. 165-170.

[14] M. Terziovski, The relationship between networking practices and business excellence: a case study of small to medium enterprises (SMEs), Measuring Business Excellence, Vol. 7, No. 2, 2003, pp 78-92.

[15] A.C. Caputo, F. Cucchiella, L. Fratocchi, P.M. Pelagagge and F. Scacchia, A methodological framework for innovation transfer to SMEs, Industrial Management \& Data Systems, Vol.102(5), 2002, pp 271-283.

[16] N2018/00533/FÖF, Uppdrag att genomföra ett program för ett robotlyft riktat till små och medelstora industriföretag.

[17] Eurostat, $25 \%$ of large enterprises in the EU use robots, published in 21/01/2019.

[18] P. Purohit and T.C. Kandpal, Techno-economic evaluation of water pumping windmills in India, International Journal of Global Energy Issues (IJGEI), Vol. 21, No. 3, 2004, pp. 263-275.

[19] M. Karhenas and P. Stoneman, Technological Diffusion, In Stoneman P. (Ed.), "Handbook of the Economics of Innovation and Technological Change", Blackwell Publishers Ltd, Cambridge Massachusetts, ISBN 0-631-17773-6, 1995.

[20] E.M. Rogers, Diffusion of Innovations, Free Press, New York, ISBN 0-7432-2209-1, 2003.

[21] J. Damsgaard and K. Lyytinen, Contours of diffusion of electronic data interchange in Finland: Overcoming technological barriers and collaborating to make it happen, Journal of Strategic Information Systems, Vol. 7, 1998, pp. 275-297. 